\title{
A New Deal for Political Space: what effect could space have on attitudes to the New Deal for Communities?
}

\author{
Deirdre Duffy*1 \\ University of Nottingham
}

\begin{abstract}
Summary
The dynamics of engagement, particularly at a local level, have been a key concern of New Labour's political discourse. Drawing on theoretical models such as social capital and social cohesion, the government has invested both time and capital into increasing 'active citizenship', particularly in economically deprived and socially marginalised areas. The flagship of this policy approach has been the New Deal for Communities (NDC) programme. This ten year initiative, which led to the formation of local partnership boards in 39 of the most deprived areas in Britain, has been the subject of much analysis both by practitioners and academics and a wealth of data has been gathered regarding the social, economic and political characteristics of the NDCs. However, conspicuous by its absence from NDC evaluations has been the 'geographic' issues of space and scale and the impact 'the politics of scale' may have on the NDC programme. For this reason, this article aims to explore the potential applications of these geographic debates within NDC research and to critique NDC through the lens of the politics of scale.
\end{abstract}

Keywords: New Deal for Communities, space, politics of scale, devolution, Thirdspace.

\section{Introduction}

Increasing civic participation has been a key policy aim of the New Labour government. Using terms such as 'social cohesion' and 'social capital', New Labour have tried to cement the idea that public participation in the political process is at the core of a functioning liberal democracy. The central focus of this political strategy, embodied in the discourse of the Third Way and 'rights and responsibilities' agenda, has been the reform of local governance structures. Underlining the importance of 'community' and 'active citizenship', old fashioned systems of representative democracy and bureaucratic-technocratic decision-making and policy implementation were to be 
p.40. A New Deal for Political Space: What effect could space have on attitudes to the New Deal for Communities?

superseded by more participative mechanisms of community consultation and involvement in which citizens were encouraged to take a more active, rather than passive, role in local politics (Flint and Raco, 2001).

At base, this was a policy shift from former Conservative-led centralising policies to what could be dubbed 'micro-devolution'. In an effort to move away from traditional attitudes to how policy formation should be divided (economic policies at a national level, infrastructure management at a local level and so on), this policy approach tries to devolve policy-making abilities to the lowest possible level (such as school management committees or neighbourhood management schemes such as 'New Deal for Communities' Resident Boards). This is influenced by two theoretical models. The first, that driven primarily by the writings of Etzioni (1996), Coleman (1990) and Putnam (2000), amongst others, is that further civic engagement, or increased 'social capital', stabilises civil society and makes liberal democratic states function better. As Etzioni stipulates, in order to maintain the balance between social order and personal autonomy, a 'community of communities' needs to develop where constituent communities can mediate between the needs of members of the communities and the status quo. However, it is worth noting that social capital theory as proposed by authors such as Putnam (2000) has been critiqued by many others. Key amongst these is the 'Bad Civil Society' model proposed Chambers and Kopstein (2001) which argues that people may engage and 'build' social capital in a number of negative ways such as involvement in discriminatory organisations or criminal groups.

The second theoretical model is rooted in ideals of political participation and efficacy. Sustained by the empirical work in the US by Verba, S., et al. (1995) and the analysis of the Citizens' Audit by Pattie et al. (2003) which suggested that people were more likely to participate in politics 'beyond simply participation in elections' at a local level than at the level of central government. This line of argument proposes that for democracy to be effective there must be multiple opportunities for democratic participation and the most effective avenues for participation lie at a local level. As Pratchett (2004) comments:

Local democracy ... builds and reinforces notions of participatory citizenship, because it is the primary venue in which most people practise politics. It follows that, without some form of local democracy, the opportunities for developing democratic values and skills that can be used at broader institutional levels would be severely limited. Consequently, local democracy provides the foundation for strong national democratic institutions and practices ... [W]ithout a vibrant participatory democracy at the local level, representative democracy at both the local and broader level cannot flourish. (Pratchett, 2004: 359)

However, although both of these theoretical models present quite valid arguments, as this article will illustrate, there are other theories which can provide a better explanation for the dynamics of what we shall call micro-devolution. Using the example of New Deal for Communities Partnership Boards, this article highlights the limitations of using either social capital theory or theories of political participation as explanatory models for political engagement at this level and propose that conceptualisations of 'the politics of scale' and 'Thirdspace' (Soja, 1993) may be more useful in this case. It shall posit the idea that, while social capital theory provides a good indication of how circles or networks of social engagement can influence micro-devolution, the theory falls short in that it doesn't take into account what people perceive as a 'legitimate' political scale or space. 
p.41. A New Deal for Political Space: What effect could space have on attitudes to the New Deal for Communities?

By outlining the key elements of the politics of scale debate and placing these arguments within the NDC framework, this article aims to compare existing geographic theories of the politics of scale with NDCs to suggest what looking at NDCs and microdevolution in this way could add to discussions of the dynamics of political participation at this level.

\section{Politics of Scale}

Interest in scales and different spatial constructions in both human and physical geography is not new (see: Marston, 2000). However, debates regarding the relationships between scales, the ways in which political contests move up and down scales, and even the constitution or substance of scales themselves are relatively recent phenomena (Cidell, 2006). Accepting that space cannot be conceptualised in terms of social constructionism or geographic boundaries alone, proponents of the politics of scale have argued that a key element of discussions of scale needs to be how scales operate as vehicles for social relations, engagement and participation. Put simply, in order to understand the complexities of how policy issues are spread across local, regional or national levels, for example, then we must discuss scaled places which are 'the embodiment of social relations of empowerment and disempowerment and the arena through and in which they operate' (Swyngedouw, 1997: 169).

Fundamentally, the term 'politics of scale' refers to the idea that geographic scales within political discussions such as local, regional and global should not be taken for granted but should be explored as social constructions which can affect how political systems work or our perceptions of how they should work. Theorists investigating the politics of scale approach these divisions as areas where physical space ("the geographic'), political divisions ('the political') and perceived boundaries or borders ('the social') meet. As political levels or scales, these areas are created and maintained by our perceptions and this can have an immeasurable affect on policymaking and framing. For example, why are some issues (such as trade) considered 'regional' and some 'national' even though policy decisions could have serious ramifications at both levels? As Delaney and Leitner (1997) comment, the common ground of research into the relationship between politics and scale is that geographic scale in conceptualised as socially constructed rather than ontologically pre-given, and that the geographic scales constructed are themselves implicated in the constitution of social, economic and political processes. Essentially, what falls under the remit of 'local government' or 'national government' is not pre-determined by geography but rather constructed by social experiences and norms or, in the words of Neil Smith (1992: 73), the differentiation of geographical scales is established through the geographical structure of social interactions.

One of the key figures in the development of the politics of space is Henri Lefebvre (1991) who observed both that space is a social product and that discussants of the politics of scale needed to be wary of forsaking the physical for the conceptual. Lefebvre's work sought to underline the interaction between conceptualisations of physical geography and social constructionism and propagated the idea that social norms could influence spatial divisions and vice versa. Lefebvre's hypotheses was expanded by the work of John Agnew (1993; 1995; 1997) whose analysis of the mani puliti ('clean hands') scandal and the subsequent political collapse in Italy between 1992 and 1994 investigated the relationship between modes of political action and scales. The scandal, which led to the indictment of many leading political figures on corruption charges, signalled the end of the old party system and created, in Agnew's 
p.42. A New Deal for Political Space: What effect could space have on attitudes to the New Deal for Communities?

view, a new politics of scale centred on the reorganisation of the political parties. In the words of Marston (2000):

What Agnew means is that understandings of geography - especially the tensions that exist around national, regional and local issues and identities - have shaped the ideology and organisation of the main political parties in Italy as they have reconstructed themselves in the wake of the collapse of the old party system in the early 1990s. As he writes (1997: 118) 'Political parties organise themselves and their messages through the ways in which they divide and order space. The boundaries they draw, tentative and contingent as they may be, define the geographical scales that channel and limit their political horizons.' (Marston, 2000: 222)

Agnew's theorisations, coupled with those of Ander Herod whose study of contract bargaining amongst Longshoremen in the United States (1995; 1997a; 1997b) focussed on the scales at which bargaining occurs and has been said to have reshaped the geography of the long shore industry in the US (Marston, 2000), place interactions between policy, social norms and geographic spaces at the crux of social engagement and participation. According to their evaluations, within any given political system, there is an intimate relationship between how policies function, the geographic level (or scale) the policies function at and our perceptions of the boundaries of that area and that changes in each of these three features affects or is affected by changes in the other two.

If we accept this as true, that the dynamics of social engagement and political action are influenced by social norms and the scale at which something takes place, then the issues covered by discussions of the 'politics of scale' could have some relevance for discussions regarding the dynamics of 'micro-devolution' or neighbourhood-level politics. For this reason, the second section of this article will combine theories of the politics of scale with the NDC programme and demonstrate the theory's practical applications in evaluations of the evolution of political action and participation at this level.

\section{New Deal for Communities and the Politics of Scale}

Building on the topics covered in the preceding section, this article will now turn to how the concept of 'politics of scale' relates to recent programmes targeted at creating a culture of engagement and political activity amongst deprived neighbourhoods, in particular the New Deal for Communities area-based partnerships. By applying the theory of politics of scale to NDC this article shall explore the relevancy of the politics of scale debate in an area which has thus far primarily used theories of political science such as models of deliberative democracy, local governance and the social capital debate.

Thus far participation in neighbourhood-level politics has been discussed using theories of social capital, rational choice and political action rather than conceptualised in terms of space. Existing commentaries route the decision to engage in politics in individualised cost-benefit analyses (Olson, 1965) and underline the positive influences the social circles or networks people move in (Heath, 2004) and their attitudes to politics generally (see: Mathers, et al., 2008) can have on political engagement. For example, one study by Pattie and Johnston (2001) examines the affect conversations between people can have on their political activism and another by Mathers, et al (2007) identifies people's opinions of what could loosely be dubbed 
p.43. A New Deal for Political Space: What effect could space have on attitudes to the New Deal for Communities?

political actors (such as, social services, local authorities) as a barrier (or facilitator) to engagement.

While the findings from these studies are a useful resource for investigations of why people engage with NDCs, they do appear to overlook the socio-spatial element to political engagement at this level. Though previous research has underlined the effect neighbourhoods have on political activism (Forrest and Kearns, 2001) and social capital theory does place a substantial emphasis on place-based identity in the form of community, geographic space and scale seems to be ignored in theoretical discussions of political engagement in NDC. Nevertheless, if we compare some of the ideas raised in the previous section of this paper with the theories which are most referenced by commentators on the subject, we can see that the politics of scale could be extremely relevant to the political participation debate.

One of the most dominant theoretical models within discussions of the limitations or facilitators to engagement with NDCs is social capital theory. The argument here, albeit a circular one, runs that political activism will increase the stronger the ties between both members of the community and members of different communities and these ties will have a positive influence on political activism in the future. In terms of an effect on the NDC programme, social capital theory appears to suggest that by investing in community initiatives and increased social cohesion or stronger social networks, political participation will increase and people will become more active in the formation of policies which affect their area. However, this argument raises a number of issues and some theorists such as Levi (1996) have criticised social capital theory of conflating the fact that people who are engaged in a number of different community groups are often also politically active with the idea that membership of community groups leads to political activism. Social capital also doesn't explain why NDC Board elections in neighbourhoods which have a number of particularly vibrant community groups don't necessarily receive a high turnout or why elections are often uncontested (see: Duffy, et al., 2008).

Although this seems to be a contradiction in terms, some of these contradictions could be explained using a politics of scale framework. If we look at the hypothesis put forward by Soja (1993), for example, it becomes clear that social capital theory is not so much inaccurate as self-limiting in the lack of credence it gives to spatial factors. Soja's argument, demonstrated through the example of the city of Los Angeles, asserts that for a place to be accepted by people as a legitimate political space (a Thirdspace), it must be accepted as both a distinct geographic space and a social space. Social capital theory encompasses the first two elements of this - the interrelationship between social activity and political activity - but fails to take into account the necessary for political spaces to be imagined as a distinct geographic area.

The role geographic space can play in engagement in NDCs was also underscored by interviewees in a recent empirical investigation of what influenced turnout in NDC Board elections. Over the course of 27 interviews with Board members and NDC staff, it became clear that many of the people involved in NDC felt that election turnout was limited by how the NDC area was constructed. As one staff member surmised, it was hard for them to mobilise residents to vote in elections as the NDC area 'wasn't real' (Duffy, et al., 2008). Another resident Board member commented that people in their section of the NDC did not really associate with the NDC area as a political space because their estate was separated from the other parts of the NDC area by a motorway. Due to this separation, they felt that people tended not to view the estate as occupying the same 'real' geographic space as the rest of the NDC.

These comments of course raise a whole host of other issues around what constitutes 'real' space but for the purposes of this promotion of using the 'politics of 
p.44. A New Deal for Political Space: What effect could space have on attitudes to the New Deal for Communities?

scale' in evaluations of political engagement at NDC level, it is enough to emphasise that comments such as this exemplify the fact that the mobilising abilities of NDCs are restricted by the fact that they lack the geographic element of Soja's conceptualisation of what counts as political space. This could suggest that the rationale for or limitations of political activism at an NDC level could be explained better using theories of political space or scale that social capital theory. 'Politics of scale' also underlines how counter-productive the relatively arbitrary formation of NDC areas has been on their participatory potential.

As well as this, using the theory of politics of scale, specifically the idea that there is an intimate relationship between the geographic scale at which policies function and how policies function, could help us map how policy management should be divided in NDC areas. While much of this mapping will be theoretical and, in accordance with the theory of politics of scale, these divisions cannot be codified, exploring the limits to devolving policy management using the idea that viable political scales must be a combination of 'the geographic', 'the social' and 'the political' may provide a useful starting point for further empirical analysis into how far micro-devolutionary practices can be stretched. Considering that recent policy initiatives appear to favour the view that by devolving policy-formation to the lowest possible level will imbue people with a greater sense of civic responsibility and facilitate the growth of social capital, theoretical conceptualisations of what policies work, where they work and why they work in terms of geographic divisions and space of social movement or engagement could provide a very useful insight into the dynamics of political engagement at a neighbourhood level. In the case of NDC, for example, as the boundary-making was deprivation-driven (driven by social issues) and didn't really take into account other geographic or political factors, 'politics of scale' theory helps explain why, as Duffy, et al (2008) highlight, their potential to act as functioning political spaces is limited. Put another way, the construction of NDC boundaries focused disproportionately on 'the social aspect' and ignored 'the geographic aspect' and this has inhibited 'the political aspect'.

In addition, and on a somewhat more basic level, the theory of the politics of scale bridges some of the 'investigatory gaps' within analyses of the praxis of microdevolution. Unlike social capital theory, or even debates regarding what counts as a locality (broadly defined as the 'new localism' debate), which tend to focus on one aspect of micro-devolutionary engagement or neighbourhood-level participation, the politics of scale tries to take a triadic approach. Rather than attempting to account for participation or non-participation in terms of the 'social connectedness' (social capital) or political identity (identity politics or regionalism), the politics of scale tries to illustrate spheres of political action, social networks and the social construction of space as one interlinked and indivisible theoretical 'entity'. 'Politics of scale' could also provide a useful way to critique micro-devolution (or 'double devolution') practices, something which is often assumed to be inherently positive, as it highlights the lack of geographic consideration given to devolutionary policy initiatives and the effect this could have on their success. In this way, it has the potential to provide a useful framework for analysis of neighbourhood-level political systems or areas of microdevolution such as NDC.

However, there is quite a strong counterargument to this which is that theories of 'imagined' space or perceptions of political scale often put too much emphasis on describing conceptual variables and not enough on investigating practical applications. While highlighting the impact the social construction of space can have on a political system or on levels of political participation is important, other than the studies conducted by Agnew (1993; 1995; 1997) and Marston (2000) few empirical studies 
p.45. A New Deal for Political Space: What effect could space have on attitudes to the New Deal for Communities?

into the effect using a 'politics of scale' framework could have on the praxis of local politics - or neighbourhood-level politics for that matter - exist. For this reason, despite the cogency of the commentator's theoretical arguments, given the lack of data analysis, these arguments are restricted to theory alone. Notwithstanding this, as this article has attempted to show, there is scope for research using the theory of politics of scale and future researchers should take this into consideration.

\section{Conclusions}

Overall, this article has attempted to illustrate the gaps in current discussions of devolution to a neighbourhood level, specifically with regard to the relationship between perceptions of what constitutes a political space and the dynamics of political participation at this level. By focussing on geographic theories of the politics of scale rather than more 'socio-political' theories of social networks and social capital, this article has illustrated the potential for using the politics of scale as a framework for future analysis. Although this article has been largely theoretical, it has raised some interesting questions regarding the influence space or normative conceptualisations of political scale could have on attitudes to modes of micro-devolution such as the NDC programme. It has also sought to underscore how explicators for engagement or nonengagement such as social capital theory fall short in that, while they pay a substantial amount of time evaluating the impact of strong or weak social networks, they appear to pay comparatively little attention to the geography of political action or engagement. Ultimately, by discussing NDC and micro-devolution in this way, this article has asked, if NDC and micro-devolution are all about conceptualising neighbourhood areas as political spaces, why we aren't asking about political space?

\section{Notes}

1 This article uses evidence from the 2008 Centre for Regional Economic and Social Research study on participation at New Deal for Communities' Board elections conducted by Prof. Peter Wells, Deirdre Duffy and Deborah Platts-Fowler on behalf of the Department for Communities and Local Government. I would like to acknowledge the help and support of William Eadson and Sioned Pearce for their comments on earlier drafts of this paper and the NDC Board members and staff who took part in the study.

* Correspondence Address: Deirdre Duffy, School of Sociology and Social Policy, Faculty of Law and Social Sciences, University of Nottingham, University Park, Nottingham, NG7 2RD. Email: deirdre.duffy@nottingham.ac.uk. Tel: 01158468128.

\section{References}

Agnew, J. (1997) The myth of backward Italy in modern Europe, in: Allen, B. and Russo, M., eds., Revisioning Italy: national identity and global culture, Minneapolis: University of Minnesota Press: 23-42.

Agnew, J. A. (1993) Representing space: space, scale and culture in social science, In: Duncan, J. and Ley, D. (eds) Place/Culture/Representation. London: Routledge. 
p.46. A New Deal for Political Space: What effect could space have on attitudes to the New Deal for Communities?

Agnew, J. A. (1995) The geographical dynamics of Italian politics, 1947-1987. In: Hochberg, L. and Earle, C. (eds) Geographical Perspectives on Social Change. Stanford: Stanford University Press.

Barnes, S. and Kaase, M. (1979) Political Action: Mass Participation in Five Western Democracies. Sage.

Chambers, S. and Kopstein, J. (2001) Bad Civil Society. Political Theory, 29, 837.

Cidell, J. (2006) The place of individuals in the politics of scale. Area, 38, 2, 196-203.

Coleman, J. (1990) Foundations of Social Theory. Belknap Press

Delaney, D. and Leitner, H. (1997) The political construction of scale. Political Geography, 16, 2, 93-97.

Duffy, D., Platts-Fowler, D. and Wells, P. (2008) Neighbourhood Governance: Making New Deal for Communities elections a significant event for partnerships and communities. London: Communities and Local Government.

Etzioni, A. (1996) The Spirit of Community: Rights, Responsibilities and the Communitarian Agenda. New York: Crown.

Forrest, R. and Kearns, A. (2001) Social cohesion, social capital and the neighbourhood. Urban Studies, 38, 12, 2125-2143.

Heath, O. (2004) Modelling the components of political action in Britain: The impact of civic skills, social capital and political support. Journal of Elections, Public Opinion and Parties, 14, 1, 75-93.

Herod, A. (1997a) From a Geography of Labor to a Labor Geography: Labor's Spatial Fix and the Geography of Capitalism. Antipode, 29, 1, 1-31.

Herod, A. (1997b) Labor as an Agent of Globalization and as a Global Agent, in: Cox, K.R., Spaces of Globalization: reasserting the power of the local, Guildford Press: 167-199.

Herod, A. (1995) The Practice of International Labour Solidarity and the Geography of the Global Economy. Economic Geography, 71, 4, 341-363.

Lefebrve, H. (1991) The Production of Space, translated by: Donald Nicholson-Smith, Oxford: Blackwell.

Levi, M. (1996) Social and Unsocial Capital: A review essay of Robert Putnam's Making Democracy Work. Politics \& Society, 24, 1, 45-55.

Marston, S. (2000) The social construction of scale. Progress in Human Geography, 24, 219-42.

Mathers, J., Parry, J. and Jones, S. (2008) Exploring Resident (Non-)participation in the UK New Deals for Communities Regeneration Programme. Urban Studies, 45, 3, 591-606.

Olson, M. (1965) The Logic of Collective Action. Harvard University Press

Pattie, C. and Johnston, R. (2001) Talk as a political context: conversation and electoral change in British elections, 1992-1997. Electoral Studies, 20, 17-40.

Pattie, C., Seyd, P. and Whiteley, P. (2003) Citizenship and Civic Engagement: Attitudes and Behaviour in Britain. Political Studies, 51, 443-468.

Pratchett, L. (2004) Local autonomy, local democracy and the 'New Localism.' Political Studies, 52, 2, 358-375.

Putnam, R. (2000) Bowling Alone: The Collapse and Revival of the American Community. Simon \& Schuster.

Raco, M. and Flint, J. (2001) Communities, places and institutional relations: assessing the role of area-based community representation in local governance. Political Geography, 20, 585-612.

Rallings, C. and Thrasher, M. (2001) A Study of Community Involvement, London: Neighbourhood Renewal Unit. www.neighbourhood.gov.uk/publications.asp? did=252. Accessed on 13/1/2009.

Smith, N. (1992) Geography, difference and the politics of scale. In: Doherty, J., Graham, E. and Makeld, M. (eds) Postmodernism and the social sciences, pp. 5779. New York: St. Martin's Press. 
p.47. A New Deal for Political Space: What effect could space have on attitudes to the New Deal for Communities?

Soja, E. W. (1993) Thirdspace: Journeys to Los Angeles and Other Real-And-Imagined Places. Blackwell: Cambridge, Mass.

Swyngedouw, E. (1997) Neither global nor local: 'glocalization' and the politics of scale. In: Cox, $\mathrm{K}$ (ed) Spaces of globalization: reasserting the power of the local, pp. 137-66. New York: Guilford.

Verba, S., et al. (1995) Voice and Equality: Civic Voluntarism in American Politics. Harvard University Press.

Wright, J.S.F., Parry, J., Mathers, J., Jones, S. and Orford, J. (2006) Assessing the Participatory Potential of Britain's New Deal for Communities. Policy Studies, 27, 347-361. 